\title{
EL MÉTODO INDICIARIO EN LAS FACULTADES DE COMPROBACIÓN DEL FISCO FEDERAL ${ }^{1}$
}

Emilio Margáin Manautou²

Sumario: 1. Introducción. 2. Clasificación del Método Indiciario. 3. El Método Indiciario. 4. Signos Externos de Riqueza 5. Estudio del Alfonso Gota Losada. 6. Utilizando medios indirectos de la investigación económica o de cualquier otra clase. 7. Su uso de 1961 a 1964 por el fisco federal Mexicano. 8. Su labor en el Estado de México 9. Estado de Sonora, Municipio de Hermosillo. 10. Capacidad abstracta de producción de la maquinaria o equipo que se utiliza y materia prima que se consume. 11. Palabras finales.

\section{Facultades de comprobación fiscal.}

\section{Introducción}

Las facultades que las autoridades fiscales federales pueden ejercer para comprobar que los contribuyentes mexicanos que cumplen cabalmente con las obligaciones fiscales a su cargo, sean impuestos o derechos, se consignan en el artículo 42 del Código Fiscal de la Federación en vigor y en ninguna de sus nueve fracciones se hace alusión al Método Indiciario como facultad de comprobación fiscal, acercándose a tal método lo dispuesto en la fracción IX, vigente a partir del 1 de enero de 2014, que nos dice: "Practicar revisiones electrónicas a los contribuyentes, ... basándose en el análisis

1 Conferencia impartida en la Facultad de la Contaduría Pública de la Universidad Autónoma de Chiapas, el dia viernes 21 de octubre 2016, a invitación del su Director Dr. Raúl Ibarias.

2 Distinguido Catedrático Emérito de Derecho Fiscal y Administrativo de la Universidad Nacional Autónoma de México y de otras Universidades Públicas y Privadas del País y del extranjero. Doctor Honoris causa por CENIJUR Centro de Investigación Jurídica Puebla. Reconocido Profesional de los Foros Jurídicos Nacionales y Locales en el ámbito Administrativo y Fiscal. Autor de mas de 20 obras en la materia actualizadas cada año, tales como: "Introducción al Estudio del Derecho Tributario", "Introducción al Estudio del Derecho Administrativo, "De lo Contencioso Administrativo de Anulación o de llegitimidad, Política Fiscal, Recursos Administrativos entre otras. "Distinguido Miembro Invitado de la Academia de Derecho Administrativo" a partir de la entrada en vigor(1991) de la Ley 4 que regula orgánicamente la vida académica de la Universidad de Sonora. 
de la información y documentación que obre en poder de la autoridad, sobre uno o más rubros o conceptos específicos de una o varias contribuciones o con más claridad lo dispuesto en el artículo 56, fracción V, de dicho Código, que nos dice:

"Artículo 56.- Para los efectos de la determinación presuntiva a que se refiere el artículo anterior, las autoridades fiscales calcularán los ingresos brutos de los contribuyentes, el valor de los actos, actividades o activos sobre los que proceda el pago de contribuciones, para el ejercicio de que se trate, indistintamente con cualquiera de los siguientes procedimientos:

......

V. Utilizando medios indirectos de la investigación económica o de cualquier otra clase."

Medio indirecto que utilizó el fisco federal de 1961 hasta 1964 y al desaparecer el grupo que supo manejarlo jamás ha vuelto a emplear para determinar créditos fiscales a los contribuyentes omisos, objeto de nuestra plática el día de hoy.

El método indiciario como facultad de comprobación fiscal es el indiciado cuando existe fuerte evasión fiscal de parte de los contribuyentes en el pago de las contribuciones a su cargo. En Francia se utilizó método durante cerca de veinticinco años para contribuyentes y los que omitían, por lo que al tener controlado el 85 por ciento del ingreso que se percibía de ellos el país, dio el paso al impuesto al valor agregado o impuesto al valor añadido como lo llama la legislación española, pero hoy, se queja dicho fisco de que la evasión tributaria tiende a crecer.

En México durante los primeros cincuenta o sesenta años del siglo pasado, los contribuyentes personas físicas y morales salvo excepciones declaraban parte de sus ingresos o utilidades de ahí que se observó que las personas físicas empresariales o profesionistas con importantes ingresos se distinguían en residir en casas que eran mansiones de elevado valor. Fue hasta que se estableció en el Distrito Federal en 1947 una importante empresa comercial norteamericana acostumbrada a producirse con 
corrección en el pago de los impuestos federales y locales de su país quien al mes de estar operando en méxico manifestó al fisco federal que cumplir con los requisitos para pagar el entonces impuesto del timbre le iba a significar un mayor pago frente a lo que le pagaría al propio fisco, observación que ninguna empresa mexicana había efectuado lo cual dio origen a que se convocará por la Secretaria de Haciedo y Crédito Público a lo que se llamó la Tercera Convención Nacional Fiscal que se celebró en ese mismo año en la ciudad de Guadalajara, Jalisco, concurriendo todos los organismos de contibuyentes del pais así como las entidades federativas; Convención en la cual manifestaron los organismos de contribuyentes que la pretensión de crear un impuesto federal sobre ingresos mercantiles originaría la destrucción del sistema tributario en vigor que era inmejorable.

Expuesta la queja del establecimiento comercial norteamericano y el por qué costaría más el cumplir con sus obligaciones y requisitos que la cantidad a pagar por concepto de impuesto del timbre los directivos de los organismos empresariales guardaron silencio.

En enero de 1948 entró en vigor el impuesto federal de ingresos mercantiles en sustitución del impuesto del timbre y el fisco federal observó cómo de inmediato se incrementó la recaudación tributaria del principal impuesto indirecto en vigor.

Bien puede sostenerse que la industria y el comercio importante se abstuvieron de inmediato de seguir eludiendo el pago correspondiente de los impuestos a su cargo, no así por algunas empresas de cierta capacidad económica y el grueso de los contribuyentes de mediana categoría hasta que se creó, en marzo de 1959, por el subsecretario de ingresos Eduardo Garduño la Dirección General de Auditoría Fiscal Federal que cobijó a todo el personal dedicado a la labor de fiscalización formado, esencialmente, por contadores públicos, pasantes y estudiantes de dicha profesión, surgiendo malestar en el grueso de los contribuyentes por cuanto que el comportamiento de ellos en el cumplimeinto de sus obligaciones fiscales se debió al 
comportamiento del personal de fiscalización que empleaba cada dirección Administradora de Impuestos, procediendo los organismos que contribuyentes a solicitar que se autoriza la regularización de su asociados que así lo solicitaran sin el cobro de los recargos ni la imposición de sanciones, ni el otorgamiento de garantía alguna, ni siquiera ingresar a los negocios.

Pero ¿Cómo realizar la labor de regularización de los contribuyentes por todo el país sin tener el fisco el derecho de examinar contabilidad alguna ni de ingresar a los establecimientos de los que regularizaran su situación fiscal?

Siendo Subsecretario de ingresos de la Secretaría de Hacienda y Crédito Público Dn. David Romero Castañeda, asignó al suscrito que era entonces sus asesor jurídico para que acudiera a resolver el problema que había surgido con los contribuyentes de Rio Verde, S.L.P., con motivo de la presencia del nuevo personal de fiscalización.

Al término de esa labor en que se regulariza al grueso de los contribuyentes de dicho municipio, quienes cubrieron otro tanto de lo pagado en el año de 1960 y aceptaran, pagar durante 1961 un 150 por ciento de incremento e incorporándose su zona agrícola, utilizándose algo del método indiciario.

Clasificación del Método Indiciario.- Luigi Einaudi en su obra PRINCIPIOS DE HACIENDA PÚBLICA, clasifica el Método Indiciario en tres clases:

a) Signos externos de riqueza;

b) Capacidad abstracta de producción o equipo de maquinaria que se está empleando y materia prima consumida; y

c) Cuota a contribuyentes pequeños, reminiscencia de la revolución francesa.

El primero lo emplean los fiscos de países avanzados para conocer el comportamiento de la persona física como contribuyente y el segundo para conocer el comportamiento de la persona moral. El primero lo utilizó el Fisco Federal mexicano de 1961 hasta 1964, el segundo de 1963 a 1964 y los suspendió al retirarse el personal técnico que lo 
habia utilizado y trasladarse a desarrollar una labor a otra Secretaría de Estado que sorprendió hasta al mismo señor Presidente de la República su comportamiento.

EI Método Indiciario.- Conforme al Diccionario de la LEngua Española, Ed. Vigésima Primera Edición, Indiciario: Relativo a indicios o derivados de ellos. Indicio.( Del Lat. Indicium) Fenómeno que permite conocer o inferir la existencia de otro no percibido.

El Segundo Tribunal Colegiado del Sexto Circuito, en el amparo directo 317/87, nos da su concepto de qué se entiende por indicio al sostener:

INDICIO. CONCEPTO DE.- El "indicio" es una circunstancia cierta de la que se puede sacar, por inducción lógica, una conclusión acerca de la existencia (o inexistencia) de un hecho a probar; por tanto, la convicción indiciaria se basa en un silogismo en el que la premisa mayor (abstracta y problemática), se funda en la experiencia o en el sentido común, la premisa menor (concreta y cierta)se apoya o constituye la comprobación del hecho, y la conclusión sacada de la referencia de la premisa menor a la premisa mayor; el indicio; por consiguiente, se diferencia de la presunción en que el dato específico y cierto, a lo abstracto une lo concreto, de lo que antecede ya se desprende sin dificultad que requisito primordial de la prueba indiciaria es la certeza de la circunstancia indiciante, o sea, que el indicio presupone necesariamente la demostración de circunstancias indispensables por las que se arguye indirecta pero lógicamente el hecho que hay que probar mediante un proceso deductivo con la misma certeza que da la prueba directa. ${ }^{3}$

El método indiciario, como facultad de comprobación fiscal, consiste en que, en el caso de la persona física se observa atendiendo a ciertos indicios económicos del negocio, de la casa en que vive y, familia que atiende, de lo que se desprende

${ }^{3}$ Semanario Judicial de la Federación, Octava Época, Tomo XIV, Julio de 1994, pág. 621 
cuál debe ser su ingreso en su actividad para que esté acorde al tren de vida que lleva, esto es, cuál es la ostentación con que se vive y si con el ingreso que se declara es posible llevar el tren de vida que se desprende del negocio o la vida que lleva el contribuyente con ostentarse una vida económica que noe s posible sostener con el ingreso que se declara, o se está en mala situación económica o se está omitiendo declarar el ingreso real que se percibe.

El primero lo utilizan los fiscos de paises desarrolados para examinar a las personas físicas y el segundo para conocer la actividad industrial o comercial que desarrolla la persona moral que se está estudiando.

El fisco federal mexicano lo empleó a fines del mes de enero de 1961 a noviembre de 1964 logrando en cuatro años con el mayor ingreso o utilidad a declararse y las diferencias a pagarse por los contribuyentes regularizadores a que, con las facilidades de pago otorgadas a los contribuyentes, para 1966, buen número por su importancia económica no volvieron a incurrir en evasión tributaria, se logró duplicar la recaudación tributaria percibida en 1960

Dicha labor la solicitaron los organismos de contribuyentes con motivo de la presencia de la Dirección General de Auditoría Fiscal federal, que vino a sustituir a los inspectores de impuestos tenían asignados y que salvo excepciones no eran contadores públicos; personal éste, contadores públicos y pasantes, que actuó inicialmente con verdadero profesionalismo creando fuerte desasosiego entre los contribuyentes al no poder arreglar "amigablemente" las visitas domiciliarias que podrías padecer.

Considerando los grandes organismos de contribuyentes que la situación imperante era culpa del propio Fisco Federal al no percatarse de la desviación de su personal, solicitaron y obtuvieron que titular de la Secretaría de Hacienda y Crédito Público autorizará situación fiscal lo hiciesen sin que el personal del fisco 
acudiera al domicilio de los contribuyentes a y sin el cobro de recargos por las diferencias de multa alguna, por grave que fuese la situación fiscal que se guardaran sus miembros, sin que tuviesen que garantizar las diferencias de impuestos a pagar que se aceptaran.

Surge con tal motivo la Delegación Especial que creó la Subsecretaría de ingresos que inició su labor en el municipio de Rio Verde, S.L.P., procediendo en los cuatro años siguientes a recorrer todas las entidades del país, salvo el Estado de Jalisco y ciertos municipios de los Estados de Veracruz y de Guanajuato.

Signos externos de riqueza.- Cuáles son esos signos que nos pueden indicar o presumir que el tren de vida que ostenta un contribuyente persona física lo denuncian como posible evasor fiscal o que pasa por una situación económica mala, requiriendo ejercer la facultad de comprobación fiscal entonces en vigor para conocer la realidad: visita domiciliaria.

Estos indicios que pueden denunciar a un mal contribuyente, son:

a) Atendiendo al lugar en que reside;

b) Atendiendo a la casa habitación en que vive

c) Atendiendo a si es soltero o casado y vehículos que posee;

d) Atendiendo al vehículo que ostenta la esposa:

e) Si es casado y con familia, si los hijos acuden a escuelas públicas o privadas;

f) Costo de las colegiaturas y erogaciones que originen el enviar a los hijos a la escuela privada;

g) Si en el período de vacaciones la familia sale de viaje;

h) Si hay festejos especiales en casa;

i) Si el contribuyente posee una casa o departamento de descanso en zona turística; etc. 
Estos y otros indicios económicos nos pueden indicar si el ingreso que se declara anualmente al erario va acorde con el tren de vida que se desprende del contribuyente.

En tratándose de la persona moral el método indiciario es el que la denuncia como evasor fiscal con simplemente examinar los datos económicos del negocio u el ingreso que declara. El problema que se presenta es cuando el contribuyente declara un ingreso acorde al tren de vida que lleva no obstante percibir un ingreso mayor y requiriendo un mayor estudio.

Estudio de Alfonso Gota Lozada.- Este estudioso español, en su obra TRATADO DEL IMPUESTO SOBRE LA RENTA, Tomo Tercero, cita en la presentación del mismo las siguientes palabras de la obra "Análisis Económico de los Impuestos" de John F. Due, lo siguiente:

"Por otra parte, es igualmente obvio que los gastos de una persona en alimentación, vestido, vivienda, recreo, etc., son gastos de consumo personal, ya que constituyen empleo directo en la satisfacción de necesidades personales. Por eso no son estrictamente deducibles como gastos necesarios para la obtención de la renta. Existen, no obstante, un número de conceptos de carácter intermedio que pueden considerarse ya sea como gastos de explotación o de consumo, dependiendo ellos del punto de vista adoptado, o de que puedan emplearse en parte para ambos propósitos".

Para Gota Lozada son "signos externos utilizables:
a) Vivienda;
b) Automóviles
c) Los inmuebles de esparcimiento y recreo;
d) Los cotos de caza y pesca deportiva;
e) Las aeronaves, embarcaciones y caballerías de lujo;
f) El número de servidores; 
g) La celebración de fiestas, recepciones o cualquiera otra manifestación que racionalmente pueda interpretarse como ostentación suntuaria, incluso las estancias con tal carácter y cierta permanencia o periodicidad en hoteles o establecimientos análogos.

h) Fiestas, recepciones y otras manifestaciones suntuarias de carácter social:

i) Estancia en hotel con carácter suntuario y cierta permanencia o periodicidad y

j) Otras manifestaciones que racionalmente puedan interpretarse como ostentación suntuaria". (Viajes distantes al extranjero con la familia)

\section{Utilizando medios indirectos de la investigación económica o de cualquier}

otra clase.- Lo expuesto lo recoge la fracción $\vee$ del artículo 56 del Código Fiscal de la Federación que la doctrina de derecho tributario conoce como Método indiciario y que las legislaciones de países avanzados utilizan para precisar si los ingresos o las utilidades declaradas al fisco para efectos del pago del impuesto sobre renta está acorde con el tren de vida que sustenta un contribuyente o la importancia de una empresa, esto es, son indicios económicos que puedan indicar el comportamiento del obligado al pago de los impuestos a su cargo, sea persona física o moral.

Los indicios se desprenden de la actividad que desarrolla la persona física y atendiendo al valor económico que se les asigna o que se desprende de ellos. Aun cuando este método se aplica a la persona física también es aplicable cuando la persona moral declara un ingreso o una utilidad no acorde a la importancia económica de la actividad que realiza, bien atendiendo al personal que emplea o le presta servicios, a los bienes que utiliza para realizar su objetivo o al tiempo que se dedica a desempeñar su actividad, así sea un turno de ocho o dieciséis o veinticuatro horas. El método le asigna a cada trabajador o empleado un valor económico consistente en el ingreso promedio que por día o semana debe producir al empleador. 
En ocasiones un giro empresarial, tintorería, emplea numeroso personal para atender en forma óptima a los clientes lo cual puede derivar del hecho de que es un giro que produce buenos beneficios económicos y debe esmerarse el contribuyente en corresponder el más mínimo detalle para satisfacer al cliente. Cuando la ley misma separa o divide por zonas a los contribuyentes y si excedan los ingresos de cierto monto quedan adscrito a una autoridad central, puede observarse que buen número de contribuyentes nunca ser objeto de vigilancia por una autoridad superior, lo cual puede ser considerado un indicio para que la autoridad fiscal proceda a estudiarlo con mayor detenimiento.

El método indiciario como facultad de comprobación fiscal debe de indicar, cuáles contribuyentes se consideran ser estudiados con mayor detenimiento por su importancia económica que de ellas se observa.

Su uso de 1961 a 1964 por el Fisco Federal.- Salvo el Estado de Jalisco y el municipio de Puebla, Pue., y ciertos municipios del Estado de Veracruz, Guanajuato el suscrito recorrió el resto del país, contando con la libertad de elegir a los contadores públicos pasantes de dicha profesión, abogados y personal administrativo, así como asignar sus honorarios pues sabía cómo iba a empezar el contribuyente, en total no más de ciento veinte personas divididos en once grupos, sus resultados fueron:

\section{Millones de pesos}

$\begin{array}{lcccrrr} & \text { ISR } & \text { \% INCR. } & \begin{array}{c}\text { ISIM } \\ \text { \% INCR. }\end{array} & \begin{array}{r}\text { Total } \\ \text { Impuestos }\end{array} & \\ 1960 & 3,628.0 & & 1,102.0 & & 10,967.0 & \\ 1961^{3} & 4,070.0 & 12.2 & 1,286.0 & 16.7 & 11,236.0 & 4 \\ 1962 & 4,723.0 & 16.6 & 1,449.1 & 11.2 & 12,826.6 & \\ 1963 & 5,475.3 & 20.4 & 1,531.7 & 6.6 & 14,646.5 \\ 1964 & 7,231.8 & 34.0 & 1,859.7 & 19.8 & 17,296.5 \\ 1965 & 8,629.8 & 17.2 & 2,108.0 & 6.2 & 20,096.4 \\ 1966 & 8,740.0 & 1.3 & 2,699.0 & 12.3 & 21,800.9\end{array}$

\footnotetext{
${ }^{4}$ Inicio de labor.
} 
"El aumento en los ingresos efectivos ordinarios durante 1961 se debió principalmente a mayores recaudaciones de los impuestos sobre la renta, sobre ingresos mercantiles y sobre la producción y comercio de bienes y servicios industriales, en lo cual se refleja tanto el incremento de la actividad económica como una mejor administración. Además, en el caso de los impuestos sobre la renta y sobre ingresos mercantiles -cuya recaudación aumentó 442 millones de pesos y 184 millones, respectivamente-- influyó la celebración de convenios de regularización de causantes de los sectores comercial e industrial" ${ }^{5}$

Habiéndose asignado al Director General de ingresos Mercantiles la regularización de los contribuyentes de la Cd. de Puebla, Puebla, se me acercó para expresarme que los organismos de contribuyentes de dicha ciudad no se interesaban en sus miembros depuraran su situación fiscal, ¿que si lo podía auxiliar? Requerí el padrón de todos los contribuyentes de dicha ciudad y acompañado de un contador público visitamos un sábado su comercio. Al término de una extensa revisión visual de ellos se eligieron a los diez contribuyentes que por su importancia económica y, atendiendo los ingresos que se estaban declarando y los signos externos de riqueza que de ellos se observaban, se solciito para que nueve días después se presentarán los contadores públicos de la Dirección General de Auditoría Fiscal Federal a cada negocio el mismo día y a la misma hora con cada uno de ellos. Resultado: que las cámaras de comercio y de industria solicitaron de inmediato la regularización fiscal de sus agremiados.

Lo mismo sucedió en otro municipio del Estado de Chihuahua que es una zona agrícola, mismo procedimiento e idéntico resultado.

${ }^{5}$ Informe anual del Banco de México de 1961, pág. 33 
Labor en el Estado de México.- La labor de esta entidad se originó en noviembre de 1976, debido a una invitación que por conducto de un amigo común me extendió el señor Gobernador del Estado, Prof. Carlos Hank González, para que lo visitara en la Casa de Gobierno, preguntándome al asistir lo siguiente:

“¿En mi Estado hay fuerte evasión del impuesto estatal de ingresos mercantiles?”, contestándole que sí ¿Puede usted dar con ella? Contestándole que sí.¿Qué necesita usted para realizar esa labor? Dicha labor con el Método de Indiciario se inició en el Estado de México, visitando todos los municipios del mismo en el mes de diciembre de 1976 para conocer su comercio y su industria precisando los contribuyentes que podrían influir en el aumento de la recaudación tributaria del impuesto estatal sobre ingresos mercantiles con tasa del uno por ciento, cotejando lo que cada uno declaraba mes tras mes e iniciando las facultades de comprobación con los contribuyentes del municipio de Chalco y a su conclusión con los de Tlalnepantla y Naucalpan, para enseguida continuar con el resto de los municipios del Estado con toluca su capital.

Al año de iniciada la labor se solicitó una entrevista con el señor Gobernador para conocer su opinión sobre la labor que se venía efectuando, contestando: "Esto sorprendido de los resultados del trabajo de su personal y quisiera conocerlos, invitando a todos a comer en la casa de gobierno el día viernes de la semana próxima, a las tres de la tarde"., a lo que le contesté: "Si es comida ella le va a costar varios millones de pesos", a lo que me dijo: “¿Por qué?, contestandole: "debido a que el personal está distribuido por el Estado y para estar presente a las 15:00 hrs. en la Casa de Gobierno deben suspender su trabajo a las 13:00 hrs, para llegar a esa hora". "Pues la haré cena", concluyó él.

Dicha labor se llevó a cabo de enero de 1972 hasta 1974, poseyendo únicamente datos de dos municipios, uno chico entonces, hoy ya no, y otro de cierta importancia, lamentando no tener la información de los dos municipios más importantes en esa época, pero cuyos resultados fueron sorprendentes 
Resultados de los Municipios "A" y "B"

\begin{tabular}{|c|c|c|}
\hline \multicolumn{3}{|c|}{ Municipio "A" } \\
\hline & 1973 & 1974 \\
\hline Enero & $687,666.07$ & '’'206,024.20 \\
\hline Febrero & $424,465.41$ & 1'961,386.60 \\
\hline Marzo & $758,597.22$ & 2'087,401.60 \\
\hline Abril & $365,636.44$ & $1 ' 882,004.00$ \\
\hline Mayo & $563,878.68$ & '’709,848.90 \\
\hline Junio & $418,203.58$ & 1'988,259.30 \\
\hline Julio & $756,370.38^{5}$ & $2 ' 874,635.70$ \\
\hline Agosto & $512,752.19$ & $\underline{2} 121,366.60$ \\
\hline Septiembre & $798,763.02$ & $17^{\prime} 830,926.90^{6}$ \\
\hline Octubre & $614,046.20$ & \\
\hline Noviembre & 1'029,225.10 & \\
\hline Diciembre & $\underline{662,434.63}$ & \\
\hline Total & 7’591,738.92 & \\
\hline
\end{tabular}

Esa labor se desarrolló en el municipio en crecimiento del Estado de México y fue realizado por un contador público y cinco pasantes de contador público en 14 meses, pero que están por titularse.

\begin{tabular}{|c|c|c|c|c|}
\hline \multicolumn{5}{|c|}{ Municipio “B”' } \\
\hline & 1973 & 1974 & 1975 & \\
\hline Enero & & $17 ’ 255,562.81$ & $21^{\prime} 351,558.10$ & \\
\hline Febrero & & $13,522,095.72$ & $22 ' 625,637.28$ & \\
\hline Marzo & & $15 ’ 019,957.22$ & $21 ’ 441,196.29$ & \\
\hline Abril & $14 ’ 285,822.75$ & $19^{\prime} 679,788.00^{7}$ & $21 ' 441,196.29$ & 8 \\
\hline Mayo & $11 ’ 927,802.90$ & $16 ’ 211,741.00$ & $25^{\prime} 833,194.70$ & \\
\hline Junio & $14^{\prime} 048,080.80$ & $19 ' 102,063.20$ & $257782,141.40$ & \\
\hline Julio & $13 ' 094,835.00$ & $19 ’ 759,455.80$ & $27^{\prime} 122,055.50$ & \\
\hline Agosto & $13 ' 679,496.32$ & $19 ' 680,905.50$ & $27 ’ 875,332.00$ & \\
\hline Septiembre & $13 ’ 279,754.96$ & $18 ' 372,652.10$ & $21^{\prime} 988,252.00$ & \\
\hline Octubre & $13 ’ 789,767.85$ & $18 ' 655,608.83$ & $24^{\prime} 954,458.50$ & \\
\hline Noviembre & $13 ’ 561,981.40$ & 22'202,096.60 & $26 ’ 964,305.90$ & \\
\hline Diciembre & $17 ’ 510,351.40$ & $\underline{23} 708,560.80$ & $\underline{24} 860,861.20$ & \\
\hline Total & $125 ' 177,893.38$ & $223 ' 167,477.58$ & $292 ' 631,817.97$ & \\
\hline
\end{tabular}

Esta labor se llevó a cabo por un abogado, un contador público y seis pasantes de contador público de amplia experiencia en la labor efectuada de 1961 a 1964.

\footnotetext{
${ }^{6}$ Mes de inicio de la labor de fiscalización

${ }^{7}$ La labor se desarrolló en todo el Estado de México sin el cobro de recargos e imposición de multas.

${ }^{8}$ Inicio de labor
} 
Estado de Sonora. Municipio de Hermosillo.- Posteriormente siendo Tesorero del Estado de Sonora, Héctor Lutteroth Camou, se solicitó la aplicación del Método Indiciario realizándose el comercio y la industria de Hermosillo, capital del Estado, comparando el ingreso que se declaraba para efectos del impuesto sobre ingresos mercantiles y al término del primer mes de trabajo y concluir el plazo para el pago mensual de dicho impuesto, la recaudación del impuesto se incrementó en un 30 por ciento, desconociéndose el aumento anual al retirarse dicho funcionarios del cargo que tenía y, por ende, el suscrito.

\section{Capacidad abstracta de producción de la maquinaria o equipo que se utiliza} y materia prima que se consume.- El señor Subsecretario de Ingresos, Dn. David Romero Castañeda me comisionó para que estuviera presente. Indiciada dicha reunión el Presidente de dicha cámara le expresó al Director que en su afán de conocer con exactitud cuál era el comportamiento fiscal de sus miembros había empleado no solo a contadores públicos, sino toda clase de profesionistas y le recordaba que sin la colaboración de ellos jamás conocería la reunión informe al señor Subsecretario de lo anterior y me contestó: "Señor Licenciado: se nos está acabando el tiempo para regularizar a la industria textil, intervenga usted, a lo que respondí: "deme quince días para iniciar dicha labor", lo cual se me concedió y reuní a un economista y a un contador público, a quienes les pedí que efectuaran un estudio sobre la capacidad abstracta de producción de la maquinaria o equipo que se utilizaba por dicha industria y materia prima consumida. Se les indicó que esperaba dicho estudio en quince días y que no se presentaron para nada en la Secretaría, que adquirieron lo que necesitaban para efectuar dicho estudio.

A los quince días estaban de regreso con el estudio y $s$ les asignó un municipio del Estado de Hidalgo que tenía cuatro industrias del ramo obteniendo órdenes de visita domiciliaria para cada una de ellas a través de la Comisión Revisora de Ingresos MErcantiles dependiente de la Oficina Federal de Hacienda de la jurisdicción y al concluir el estudio de la capacidad abstracta de producción de la 
maquinaria y materia prima consumida, se dio a conocer el resultado eliminando la pérdida natural del giro no al contador público sino al técnico de ella otorgando el derecho de audiencia al contribuyente. Al término de cada una de ellas efectuaron dichos técnicos, aclaraciones que se tomaron en cuenta hasta llegar al punto de que no podían los técnicos justificar todas las observaciones admitiendo la existencia de evasión fiscal.

Con tal motivo, utilizando órdenes de visita domiciliaria expedidos por el Jefe de la Oficina Federal de Hacienda de Puebla, Puebla, se inició el examen del comportamiento fiscal de la industria textil más importante de dicha ciudad que de inmediato retiró el aparato que registraba la producción de entre veinticinco o m's máquinas y materia prima que arrojaba una producción mayor a la asentada en los libros de contabilidad informando de ello al directivo de la empresa. De inmediato se presentó el contador público que había emitido el dictamen del ejercicio revisado para reclamar que él no reconocía omisión alguna, que su dictamen estaba elaborado con la debida técnica contable. Al día siguiente por la tarde se presentó pidiendo disculpas por lo que nos había dicho pues se le había informado por la cabeza de la empresa que si habia omisión de ingresos, lo cual, a su vez, denunciaba a todo un giro comercial que adquiere lo omitido por las empresas textileras.

Al visitar al fisco francés se me dio conocer los estudios que había hecho con apoyo en los signos externos de riqueza, como atendiendo a la capacidad abstracta de producción de la maquinaria o equipo utilizado y materia prima consumida, que lamentablemente el fisco mexicano desatendió.

Con motivo de la labor desarrollada se incorporaron a la tributación federal el grueso de las zonas agrícolas y ganaderas del país que estaban al margen del pago de impuestos; sí como las zonas turísticas portuarias que en Semana Santa 
ocupan totalmente los hoteles y restaurantes; fechas en que se mueve la economía del país como el mes de mayo por el dia 10 del mismo y periodo Navideño; descubriendo que el mes de noviembre es más importante que diciembre: los periodos de cosecha en las zonas agrícolas; la exportación del ganado hacia el vecino del norte, la incorporación de la cuota fija a los llamados contribuyentes menores, que se desnaturalizo con la corrupción que aflora al desaparecer la Delegación Especial de la Subsecretaría de Ingresos; creación de nuevos impuestos que tuvieron pocos años de vigencia; dificultad para incorporar a la tributación a quienes se dedican a la pesca; a la explotación de los bosques, etc.

\section{Palabras finales.-}

¿Por qué el Método Indiciario no sé emplea por el Fisco Federal si el grueso de los contribuyentes medianos o supuestamente medianos en el país es omiso en declarar el ingreso real que percibe en la actividad que desempeña, sea pequeño, mediano, grande o muy importante? ¿Por qué no se realizan estudios técnicos de cada ramo o giro de la industria que opera en el país? Cuál fue el destino de ese grupo que llevó a cabo la labor de regularización fiscal? Desarrolló de enero de 1965 a noviembre de 1970, labor de vigilancia de las inversiones públicas federales que llamó la atención del entonces Presidente de la República quien se convirtió en la sombrilla política del suscrito no obstante que jamás me llegó a conocer personalmente, y todo ese personal se separó del sector público para dedicarse al libre ejercicio profesional. 